\title{
Time Trends Regarding the Association Between Drug and Tabacco Consumption Among Students from the West Part of Romania
}

\author{
A transversal population study
}

\author{
MIHAELA DIANA POPA\#, ADELINA CHEVERESAN, AMADEUS DOBRESCU\#, IULIA CRISTINA BAGIU*, DELIA IOANA HORHAT*, \\ RAZVAN SUSAN, SIMONA POPESCU, CIPRIAN PILUT, RAZVAN NITU, GEORGE DAHMA, BRIGITHA VLAICU, \\ RADU VASILE BAGIU \\ Victor Babes University of Medicine and Pharmacy, Timisoara, Discipline of Microbiology, 2 Eftimie Murgu Sq., 300041, \\ Timisoara, Romania
}

\begin{abstract}
The present research was conducted in order to investigate the tobacco smoker status and intensity in relation to marijuana consumption in students of Timis County, Romania. The representative sample of 2076 students in Timis county, 62.49\% girls and 37.51\% boys, with the mean age of 21.09 years, was included into a transversal populational study. The sample included $31.1 \%$ tobacco smokers and $67.5 \%$ nonsmokers. Regarding the tobacco smoking intensity during the previous month, $11.4 \%$ smoked between 1-5 cigarettes a day, 8\% smoked between 6 and 10 cigarettes a day, 12\% smoked more than 10 cigarettes a day, the consumption being significantly higher in boys than in girls. Tobacco smoker students consumed marijuana 8.3 times more frequently than nonsmokers. Heavy smoking students were more frequently marijuana co-users than those smoking tobacco at medium intensity. Tobacco smoker students consumed marijuana 11.44 times more frequently during the prevuious 30 days as compared to nonsmoker students.
\end{abstract}

Keywords: students, tobacco consumption, marijuana consumption

Tobacco consumption has reached epidemic levels worldwide among adolescents and young people [1]. Most young tobacco smokers become adult smokers. Half of adult tobacco smokers die prematurely due to tobacco smoking related diseases [2-5].

Adolescents and young people who do not use tobacco have reduced chances to use other substances, while those consuming tobacco have an increased chance to use other substances and practice other high risk behaviors [6-9].

The affiliation of adolescents and young people to friends practicing risk behaviors, especially substance abuse, is a strong predictor for taking over such behaviors [10-14].

Risk behaviors influence individual and community wellbeing and generate many additional economic and social costs $[15,16]$. Temporal associations between marijuana use and serious adverse events, including myocardial infarction, sudden cardiac death, cardiomyopathy, stroke, transient ischemic attack, and cannabis arteritis have been described [17]. In a recent review of 163 articles, Ramo et al. [18] found that the only consistent short term consequence of co-use was exacerbation of mental health symptoms.

We decided to conduct a study on the features of tobacco associated to marijuana consumption in students.

\section{Experimental part}

Material and methods

A representative sample of students included 2076 young people in higher education institutions of Timis county, $62.49 \%$ (1296) girls and $37.51 \%$ (778) boys. The mean age was 21.09 years, SD 1.48, age interval 18-25 years.

The work method was a transversal populational study based on the CORT 2004 questionnaire on health risk behaviors in adolescents and young people. The questionnaire was validated by the Ethics Committee of the Victor Babes University of Medicine and Pharmacy \$imi-oara.
The study received written approval from the Timis county higher education institutions involved.

Subjects were only included only freely expressed consent was received from each participant, according to individual rights.

Data processing and interpretation was done using modern methods of advanced medical statistics with the PASW 18 (SPSS 18) 2010 programme. The threshold for statistical significance was set at $p<0.05$, except situations requiring the Bonferroni correction, where the accepted threshold was explicitely stated. For ordinal data comparisons we used the Mann-Whitney and KruskalWallis tests. The chi-squared test was used for ordinal/ nominal data. For co-use prediction logistic regression was involved.

\section{Results and discussions}

Tobacco smoker status and intensity of smoking

Students with affirmative answers for both questions on frequency and intensity of tobacco consumption during the previous month were classified as active smokers. Depending on the smoking status there are $31.1 \%$ (646) active smoking students and $68.5 \%$ (1402) non-smokers.

We classified students depending on the number of cigarettes smoked daily, according to Kouvonen et al. [19]. Thus, in our study we have: $11.4 \%$ (236) students smoking with mild intensity i.e. 1-5 cigarettes a day, 8.0\% (166) students who smoke with medium intensity i.e. 6-9 cigarettes a day and $12.0 \%$ (249) students smoking with an increased intensity, described in literature as heavy smokers.

\section{Marijuana consumption}

Fortysix (3.3\%) of the nonsmokers admitted marijuana use, while within the group of tobacco smokers the use of marijuana reached $22.2 \%$ (141). 
Tobacco smoking students consumed marijuana 8.3 times more frequently than nonsmoking students, $\chi^{2}=184.53, p 53, p<0.001$.

Considering only the group of tobacco smokers, we found that smoking intensity is influenced by marijuana use, $H(2)=14.57, p<0.01$. We applied Mann-Whitney tests to investigate this result. We applied the Bonferroni correction and the effects were reported to a significance level of 0.0167 . We found that students with a high intensity of tobacco smoking consumed marijuana more frequently than students who smoke tobacco at a medium intensity, $U=17004, z=-3.29, p<0.01$, and there are no differences between students who smoke at medium and low intensity where marijuana consumption is concerned (table $1)$.

Co-use was observed in 7.0\% (141), 24.5\% (493) using only tobacco and $2.3 \%$ (46) using only marijuana; $66.3 \%$ (1335) are non-users.

Tobacco smoking students used marijuana 11.44 times more frequently during the previous 30 days as compared to nonsmokers, $\chi^{2}=31.04, p<0.001$. When comparing to nonsmokers, the risk for tobacco smokers to co-use marijuana during the previous 30 days was 2.74 with $95 \%$ $\mathrm{Cl}(2.26-3.31)$.

Using only the students that smoked tobacco and/or marijuana, direct logistic regression was performed to assess the impact of entourage's habit of consuming marijuana and drugs and own intensity of smoking, as well as gender and age on the likelihood of co-use of tobacco and marijuana during the last 30 days. The model contained 7 independent variables (friend's habit of smoking marijuana, father's, mother's, and brother's consumption of any drugs, the intensity of own cigarette smoking, age and the gender) was statistically significant $\chi^{2}(7)=28.3$, $p<0.001$, indicating that the model was able to distinguish from students which used or did not use marijuana during the last 30 days. The model as a whole explained between $5.7 \%$ and $23.5 \%$ the variance of marijuana consumption and correctly classified $96.9 \%$ of all cases. Four predictors were statistically significant. Mother's consumption of drugs recorded an $\mathrm{OR}=31.2, p=0.011$. This indicated that the students with mothers that consume drugs were over 24 times more likely to co-use tobacco and marijuana in the last 30 days, controlling for all other factors in the model. Male gender recorded an $\mathrm{OR}=5.7, \mathrm{p}=0.013$. This indicated that compared to females, men were over 5 times more likely to co-use tobacco and marijuana in the last 30 days, controlling for all other factors in the model.

Friends that consume marijuana have an $\mathrm{OR}=5.3$, $p=0.005$ indicating that the students with friends that smoke marijuana are over 5 times more likely to co-use tobacco and marijuana.

Father's and brothers' drug consume and the intensity of cigarette smoking did not contribute significantly to the model (table 2).

According to published studies, there is a strong association between tobacco smoking and the consumption of other substances. Also the binge drinking habit is related to the suicidal thoughts and plans, feeling of sadness [20].

The surveillance performed in the UK in 2010 [21], showed that pupils who used drugs at least once during the previous year, had an 11 times increased chance to be a regular smoker as compared to pupils who never used drugs.

In a cohortstudy [22] on adolescents, the daily tobacco consumption was associated with an increased risk of marijuana and other ilegal drugs use, and with behavior disorders including multiple substance use. Marijuana use was associated with greater reported nicotine addiction among adolescent smokers, suggesting a potential role of marijuana in nicotine addiction [23].

Marijuana consumption, heavy smoking habit was also associated with the risk of traveling with drivers who consumed alcohol [24].

A 10 year follow-up [25] from 2003 to 2012 which monitored the co-use of tobacco and marijuana showed that marijuana use increased among past-month tobacco users and tobacco use declined among past-month marijuana users. Recently in a longitudinal trial [26-29] it was shown that symptoms of depression were related to marijuana use frequency in male users and high frequency of marijuana use was associated with increased cigarette use frequency, especially among males who had higher symptoms of depression.

Table 1

PERCENT DISTRIBUTION OF STUDENTS ACCORDING TO MARIJUANA CONSUMPTION AND INTENSITY OF TOBACCO SMOKING

\begin{tabular}{|c|c|c|c|c|c|}
\hline \multirow{2}{*}{\multicolumn{2}{|c|}{ Marijuana use ever (yes/no) }} & \multicolumn{3}{|c|}{ Smoker status intensity } & \multirow[b]{2}{*}{ Total } \\
\hline & & mild smoker & medium smoker & heavy smoker & \\
\hline \multirow{2}{*}{ No } & Number & 190 & 138 & 169 & 497 \\
\hline & $\begin{array}{l}\% \text { based on the intensity of } \\
\text { smoking }\end{array}$ & $81.5 \%$ & $84.1 \%$ & $69.8 \%$ & $77.8 \%$ \\
\hline \multirow{2}{*}{ Yes } & Number & 43 & 26 & 73 & 142 \\
\hline & $\begin{array}{l}\% \text { based on the intensity of } \\
\text { smoking }\end{array}$ & $18.5 \%$ & $15.9 \%$ & $30.2 \%$ & $22.2 \%$ \\
\hline \multirow[t]{2}{*}{ Total } & Number & 233 & 164 & 242 & 639 \\
\hline & $\begin{array}{l}\% \text { based on the intensity of } \\
\text { smoking }\end{array}$ & $100.0 \%$ & $100.0 \%$ & $100.0 \%$ & $100.0 \%$ \\
\hline
\end{tabular}

\begin{tabular}{|l|r|r|r|r|r|}
\hline & \multicolumn{1}{|c|}{ B } & \multicolumn{1}{c|}{ S.E. } & df & Sig. & Exp(B) \\
\hline Gender & 1.745 & .702 & 1 & .013 & 5.725 \\
\hline Age & -261 & .167 & 1 & .118 & 1.298 \\
\hline Father uses a drug & -18.585 & 19724.204 & 1 & .999 & .000 \\
\hline Mother uses a drug & 3.440 & 1.352 & 1 & .011 & 31.181 \\
\hline Brothers use a drug & -432 & .883 & 1 & .625 & 1.541 \\
\hline Friends use marijuana & 1.662 & .595 & 1 & .005 & 5.272 \\
\hline The intensity of smoking & -321 & .336 & 1 & .339 & 1.379 \\
\hline Constant & -11.717 & 3.734 & 1 & .002 & .000 \\
\hline
\end{tabular}

Table 2

FACTORS INCLUDED IN THE PREDICTION MODEL FOR THE DECISION TO USE A DRUG (MARIJUANA) ANDTHE INTENSITY OF CIGARETTE SMOKING 


\section{Conclusions}

Depending on the tobacco smoker status in the representative population of Timis county students there are $31.1 \%$ smoker and $67.5 \%$ nonsmoker students.

Reported to the number of cigarettes smoked daily during the previous month, among smokers $11.4 \%$ smoked between 1-5 cigarettes/day, 8\% smoked between 6-10 cigarettes/day, $12 \%$ smoked over 10 cigarettes/day reaching the heavy smoker status. Boys smoked significantly more cigarettes a day than girls.

Among nonsmokers, 3.3\% used marijuana, while in cigarette smokers the percent of marijuana users is $22.2 \%$. Smoker students consumed marijuana 8.3 times more frequently than nonsmokers. Students with a high intensity of tobacco smoking used marijuana more frequently than students who smoke tobacco at a medium intensity.

Among nonsmokers, $0.3 \%$ used marijuana during the previous 30 days, while in tobacco smokers the percent of marijuana consumers during the previous 30 days reaches $3.2 \%$. Tobacco smoking students consumed marijuana 11.44 times more frequently during the previous 30 days than nonsmoker students. The profile of tobacco and marijuana co-user during the previous 30 days is: boy, whose mother uses drugs and who has friends who smoke marijuana.

\section{References}

1.FAGERSTROM K. The epidemiology of smoking: health consequences and benefits of cessation, Drugs, 2002, 62:1-9 2.DOLL R, PETO R, BOREHAM J, Sutherland I. Mortality in relation to smoking: 50 years' observations on male British doctors, BMJ, 2004, 328:1519

3.STEINBERG L. Risk taking in adolescence: what changes, and why? Annals of the New York Academy of Sciences, 2004, 1021:51-58

4.J HA P, PETO R. Global effects of smoking, of quitting, and of taxing tobacco. New England J ournal of Medicine, 2014;370(1):60-68.

5.HOLFORD TR, MEZA R, WARNER KE, et al. Tobacco control and the reduction in smoking-related premature deaths in the United States, 1964-2012. J ama. 2014;311(2), 164-171.

6.BIGLAN A, BRENNAN PA, FOSTER SL, HOLDER HD. Helping adolescents at risk: Prevention of multiple problem behaviors. 2004. New York: Guilford Press

7.*** National Institute on Alcohol Abuse and Alcoholism. (2011). Results from the 2009 National Survey on Drug Use and Health: Volume I. Summary of National Findings. Accesat la 14Mai $2014 \mathrm{http}: / /$ www.samhsa.gov/data/2k9/2k9Resultsweb/web/2k9results.pdf

8.OLUSUNMADE M, OBAITAN I, FILIPPIDIS,F, et al. Tobacco and marijuana co-use among high school students in the US using the YRBSS (2009 \& 2011). European Respiratory Journal. 2014;44(Suppl 58), P1129

9.BAGIU, I.C., VLAICU, B., ONISEI, D., ONISEI, D., BAGIU, R.V., Types of Alcohol Associated to Binge Drinking Behaviour Among Students from Timis County, REV.CHIM. (Bucharest), 67, no. 9, 2016, p.16841687

10. HAW KINS JD, CATALANO RF, MILLER Jy. Risk and protective factors for alcohol and other drug problems in adolescence and early adulthood, Psychological Bulletin, 1992, 112(1):64-105

11. LYNSKEY MT, FERGUSSON DM, HORWOOD LJ. The origins of correlations between tobacco, alcohol and cannabis use during adolescence, Journal of Child Psychology and Psychiatry and Allied Discipline, 1998, 39(7):995-1005

12.KUENDIG H, DELGRANDE JM. Adolescents Smoking in the Crosslight of Other Substance Use and Parental and Peers' Smoking Behaviors. ISRN Addiction, 2014. Article ID 719681, http://dx.doi.org/10.1155/2014/ 719681
13.SMITH AR, CHEIN J, STEINBERG L. Peers increase adolescent risk taking even when the probabilities of negative outcomes are known. Developmental Psychology, 2014; 50(5):1564-1568. http://dx.doi.org/ 10.1037/a0035696

14.IOANA TUTA SAS, ANCUTA BANU, NICOLETA NICOLAE, et al., Particularities of the Level of Physical Activity Performed by Adolescents, REV.CHIM.(Bucharest), 69, no. 3, 2018, p. 717-719

15.*** OMSEuropean Region, European Tobacco Control Report 2007 16.HALL W, DEGENHARDT, L. The adverse health effects of chronic cannabis use. Drug testing and analysis. 2014;6(1-2):39-45.

17.THOMAS G, KLONER RA, REZKALLA S. Adverse cardiovascular, cerebrovascular, and peripheral vascular effects of marijuana inhalation: what cardiologists need to know. The American journal of cardiology. 2014;113(1), 187-190.

18.RAMO DE, HOWARD LIU H, JUDITH J. PROCHASKA JJ. Tobacco and marijuana use among adolescents and young adults: A systematic review of their co-use. Clinical Psychology Review. 2012;32(2):105121

19.KOUVONEN A, KIVIMAKI A, VIRTANEN M, et al. Work stress, smoking status, and smoking intensity: an observational study of 46 190 employees, Epidemiol Community Health, 2005;59(1):63-69

20.BAGIU IULIA, PUTNOKY SALOMEIA, TUTA-SAS IOANA, et al., Manifestations of self-harm in relation with binge drinking to students from Timis County, Romania, MEDICAL-SURGICAL JOURNAL-REVISTA MEDICO-CHIRURGICALA, 2015, 119, No.4, p.1106-1112

21 .*** Smoking, drinking and drug use among young people in England in 2010, The Information Centre for Health and Social Care, http:// www.ic.nhs.uk/webfiles/publications/003_Health_Lifestyles/ Smoking\% 20drinking\%20drug\% 20use\%202010/Smoking_drinking_ and_drug_use_among _young_people_in_England_2 010_Full_ report.pdf, accessed at 16.05 .2012

22.LEWINSOHN P, ROHDE P, BROWN RA. Level of current and past adolescent cigarette smoking as predictors of future substance use disorders in young adulthood, Addiction, 1999, 94(6):913-21

23.RUBINSTEIN ML, RAIT MA, PROCHASKA JJ. Frequent marijuana use is associated with greater nicotine addiction in adolescent smokers. Drug and alcohol dependence. 2014;141:159-162.

24.CRISTINA PANTEA, RAZVAN HORHAT, SALOMEIA PUTNOKY, et al., Risk Behaviours for Traffic Accidents in 18-20 Years Young People Travelling with Drunk Driver of Timis County, Romania, Rev. Chim.(Bucharest), 69, no. 3, 2018 p.703-706

25. SCHAUERA GL, BERGA CJ, KEGLER MC, et al. Assessing the overlap between tobacco and marijuana: Trends in patterns of co-use of tobacco and marijuana in adults from 2003-2012. Addictive Behaviors. 2015;49:26-32

26.CRANE NA, LANGENECKER SA, MERMELSTEIN RJ. Gender differences in the associations among marijuana use, cigarette use, and symptoms of depression during adolescence and young adulthood. Addictive Behaviors. 2015: 49: 33-39

27.HORHAT, RAZVAN MIHAI; VLAICU, BRIGITHA; BAGIU, RADU; et al., A Ten-year Time Laps, Regarding Drug Consumption in the Western Part of Romania, Rev. Chim. (Bucharest), 69, no. 6, 2018, p.1371-1375 28.CHIRITA-EMANDI, ADELA; BARBU, CARMEN GABRIELA; CINTEZA, ELENA ELIZA; et al., Overweight and Underweight Prevalence Trends in Children from Romania - Pooled Analysis of Cross-Sectional Studies between 2006 and 2015, OBESITY FACTS Volume: 9 Issue: 3 Pages: 206-220 Published: 2016

29.GABRIELA DOROS, CRISTINA OLARIU, ANDRADA MARA ARDELEAN, RAMONA STROESCU, MIHAI GAFENCU, Relevance of the cardiac biomarkers in children with heart disease admitted for severe cardiac pathology, Rev. Chim. (Bucharest), 68, no. 4, 2017, p. 748-753

Manuscript received: 26.08 .2018 